Review began 09/21/2021 Review ended 09/27/2021 Published 09/29/202

(c) Copyright 2021

Al-Marzouki et al. This is an open access article distributed under the terms of the Creative Commons Attribution License CC BY 4.0., which permits unrestricted use, distribution, and reproduction in any medium, provided the original author and source are credited.

\section{The Prevalence of Depression and Anxiety Among Sickle Cell Disease Patients in King Abdulaziz University Hospital}

\author{
Adel F. Al-Marzouki ${ }^{1}$, Norah I. Alrefaie ${ }^{1}$, Nora A. Aljohani ${ }^{1}$, $\operatorname{Raghad~A.~Alandanusi~}{ }^{1}$, Abdulrahman A. \\ Alghamdi ${ }^{1}$, Osman O. Radhwi ${ }^{1,2}$ \\ 1. Hematology, King Abdulaziz University Faculty of Medicine, Jeddah, SAU 2. Hematology, King Fahd Medical \\ Research Center (KFMRC), Jeddah, SAU
}

Corresponding author: Norah I. Alrefaie, noura.alrefaei@gmail.com

\section{Abstract \\ Background}

Sickle cell disease (SCD) is a recessive hereditary condition. The physical changes caused by SCD affect the quality of life (QoL) by negatively impacting psychological aspects.

\section{Objective}

This study aimed to assess the prevalence of depression and anxiety in SCD patients based on different sociodemographic characteristics in Jeddah, Saudi Arabia.

\section{Method}

A cross-sectional study was conducted at King Abdulaziz University Hospital (KAUH) in Jeddah from 13 July to 30 August 2021. The included patients were 18 years of age and above and affected with sickle cell disease. Medical staff interviewed the patients and filled the Patient Health Questionnaire (PHQ)-9 and General Anxiety Disorder (GAD)-7.

\section{Result}

One hundred nineteen (119) patients were included in this study. The median age of participants was 32 and mostly male $(n=72,60.5 \%)$. The rate of depression was $45.4 \%$. On the other hand, the rate of anxiety was $22.7 \%$. The median of the PHQ- 9 score was $8 \pm 8$ while the median of the GAD- 7 score was $5 \pm 8$. Moreover, the study showed that anxiety and depression in relation to sociodemographics were higher in the patient age groups of 30-34 years old, male, single, unemployed, and with higher education. There was a significant association between depression rate and the two variables: patient employment status $(49.3 \%$; $p=0.047)$ and a family history of SCD (51\%).

\section{Conclusion}

Depression in patients with sickle cell disease is prevalent and correlated to demographic and social factors.

Categories: Internal Medicine, Psychiatry, Hematology

Keywords: phq-9, gad-7, health quality of life, anxiety, depression, sickle cell beta-thalassemia, sickle cell disease, saudi arabia

\section{Introduction}

Sickle cell disease (SCD) in Saudi Arabia was first shown in the Eastern province in the 60s [1]. As a response, many regional and national screening studies were done to determine the clinical characteristics and frequency of SCD genes in various regions of Saudi Arabia [2]. Sickle cell disease is a hereditary autosomal recessive condition caused by a mutation in the beta-globin chain genes resulting in what we know as hemoglobin S [3]. Under hypoxic circumstances, usually disc-shaped red blood cells become sickleshaped, non-deformable, and poorly capable of passing through the small vessels, thus leading to ischemia presented with acute pain and, finally, organ dysfunction [4]. These physical changes have a negative impact on the quality of life (QoL) of SCD patients [5].

Several studies have noted a significant and robust relationship between depression and anxiety, which develops as a result of having a chronic disease such as hepatitis C [6], diabetes mellites [7], and rheumatoid arthritis [8].

Based on two systemic reviews, somatic symptoms, including pain, were strongly associated with increasing 
the severity of depression in patients with chronic medical illness [9-10]. Moreover, pain is a major and frequent complaint in patients with SCD. In a previous study published in 2018, 89 patients with SCD filled out questionnaires to evaluate anxiety and depression, $36.0 \%$ of them were depressed, and $29.2 \%$ were anxious. Females were more depressed (56\%) and anxious (58\%). Single and unemployed patients were more depressed than others. In contrast, the anxiety levels of the patients with high education levels were higher than those with low educational levels [11].

Another study in 2018 from the Eastern province of Saudi Arabia found that depression is prevalent in almost half (48.2\%) of patients with SCD [12]. The prevalence was high because the patients in that region suffered from the severest form of the disease, i.e., homozygous SS (HbSS). An additional paper from the Southern Region of Saudi Arabia found that depression prevalence in Jizan and Mahayel Aseer was (56.4\%) and (33.3\%), respectively [13]; and 10.3\% in the rest of the studied cities. A previous study showed that individuals with only a school education level and patients with frequent vaso-occlusive crisis (VOCs) had a more significant risk of developing depression than others. In addition, patients with a low monthly income were at nearly a twofold higher risk of developing depression [12].

A few studies were found that assess the prevalence of depression and anxiety in SCD patients based on different social and demographic characteristics, especially in Saudi Arabia, which is still a gap that needs to be clarified. Therefore, our research aimed to determine the prevalence of depression and anxiety among sickle cell disease patients at King Abdulaziz University Hospital in Jeddah City, Saudi Arabia.

\section{Materials And Methods \\ Study design and setting}

A cross-sectional study was done from 13 July to 30 August 2021 on patients with SCD either homozygous SS (HbSS) or heterozygous S with beta-thalassemia ( $\mathrm{Hb} \mathrm{S} / \beta$ Thal) who presented to King Abdulaziz University Hospital (KAUH) in Jeddah since 2006. One hundred nineteen patients aged 18 and above were included in the study, with no exclusion criteria.

\section{Data collection instrument}

The questionnaire for 119 sickle cells ( $\mathrm{HbSS}$ ) and ( $\mathrm{Hb} \mathrm{S} / \beta \mathrm{Th}$ ) disease patients was filled by medical staff (Norah A, Nora A, Raghad A, Abdulrahman A) and was conducted over the phone. Google Forms were used instantaneously, and the data were transformed to Microsoft Excel 2021 (Microsoft Corporation, Redmond, WA). The following variables were extracted from each patient: demographic characteristics (age, gender, marital status, education level, residential status, monthly household income, family history of SCD). Additionally, we administered the Arabic validated questionnaires: Patient Health Questionnaire (PHQ)-9 and General Anxiety Disorder (GAD)-7 (https://www.phqscreeners.com).

PHQ-9 was used to estimate the depression symptoms in relation to the nine most common symptoms $(\leqslant 4=$ low depression, 5-9 = mild depression, 10-14 = moderate depression, > 15 = severe depression) [14]. GAD-7: a seven-item designed to identify anxiety disorder and its relation with functional impairment and disability ( $\leqslant 4$ = low anxiety, 5-9 = mild anxiety, 10-14 = moderate anxiety, $>14=$ severe anxiety) [15].

\section{Analysis}

The data was performed using the Statistical Package for the Social Science (SPSS) version 21 (IBM Corp., Armonk, NY). The frequency test was conducted for qualitative data, and the quantitative data were presented as mean \pm standard deviation and median \pm interquartile range. In bivariate data, the chi-square test was used to assess the differences between categorical variables, and the t-test and Mann-Whitney test were used for non-parametric variables. P-value $<0.05$ was considered statistically significant.

\section{Research ethics}

The King Abdulaziz University Hospital research ethics committee approved this study (IRB 409-21), and it was carried out according to their guidelines and recommendations. The authors claimed verbal consent from each participant at the beginning of each phone interview.

\section{Results}

Out of 365 patients with SCD registered at KAUH, 119 patients agreed and were eligible to participate. Most of them were male $n=72(60.5 \%)$, and $n=47$ (39.5\%) were female. The median age of the whole cohort was $32 \pm 9$, and $n=67$ (56.3\%) were single. Patients with post-secondary level education were almost half of the cohort (43.7\%). Most of the patients in this study had secondary-level education (37\%). The monthly household income of most participants (54.6\%) was less than 3750 Saudi Riyal (SAR) (1 United States Dollar $=3.75 \mathrm{SAR}$ ). The unemployment rate amongst participants was $58 \%$, and $79 \%$ had a positive family history of SCD. See Table 1 for additional details. 


\section{Cureus}

\begin{tabular}{|c|c|c|}
\hline Variable & No. & (\%) \\
\hline \multicolumn{3}{|l|}{ Gender } \\
\hline Male & 72 & $(60.5)$ \\
\hline Female & 47 & (39.5) \\
\hline \multicolumn{3}{|l|}{ Age } \\
\hline $18-19$ years & 1 & $(.8)$ \\
\hline $20-24$ years & 28 & (23.5) \\
\hline 25-29 year & 19 & (16) \\
\hline 30-34 years & 31 & (26.1) \\
\hline $35-39$ years & 22 & (18.5) \\
\hline Over 40 years & 18 & $(15.1)$ \\
\hline \multicolumn{3}{|l|}{ Marital status } \\
\hline Single & 67 & $(56.3)$ \\
\hline Married & 43 & (36.1) \\
\hline Divorced or widowed & 9 & (7.6) \\
\hline \multicolumn{3}{|l|}{ Employment status } \\
\hline Working in the public sector & 43 & (36.1) \\
\hline Self-employed & 3 & (2.5) \\
\hline Unemployed & 69 & (58) \\
\hline Retired & 4 & (3.4) \\
\hline \multicolumn{3}{|l|}{ Residential status } \\
\hline Owner & 37 & (31.1) \\
\hline Renter & 82 & $(68.9)$ \\
\hline \multicolumn{3}{|l|}{ Monthly household income } \\
\hline Less than 1000 USD & 65 & (54.6) \\
\hline 1000-2000 USD & 33 & (27.7) \\
\hline 2000-3000 USD & 5 & $(4.2)$ \\
\hline More than 3000 USD & 16 & (13.4) \\
\hline \multicolumn{3}{|l|}{ Education } \\
\hline Primary level & 8 & $(6.7)$ \\
\hline Intermediate level & 15 & (12.6) \\
\hline Secondary level & 44 & (37) \\
\hline Diploma & 10 & (8.4) \\
\hline College level & 42 & $(35.3)$ \\
\hline \multicolumn{3}{|l|}{ Family history of SCD } \\
\hline Yes & 94 & (79) \\
\hline No & 25 & (21) \\
\hline
\end{tabular}

TABLE 1: Sociodemographics of 119 sickle cell disease (SCD) patients 


\section{Cureus}

To evaluate the systematic psychiatric aspects of patients with SCD, the PHQ-9 and GAD-7 questionnaires were applied. The median of the PHQ- 9 score was 8 (IQR \pm 8 ) and the GAD-7 score median was 5 (IQR \pm 8 ). Most of the SCD patients had no depression in the PHQ-9 score category, which equals $31 \%$. On the other hand, $47 \%$ of the SCD patients have had no anxiety, representing the highest percent according to the GAD-7 score category.

With further evaluation and statistical analysis, scores of $\leqslant 10$ on both the PHQ- 9 and GAD-7 questionnaires were taken as a cutoff value for anxiety and depression [15-16]. Therefore, our study presented that the rate of depression equals $45.4 \%$ while the rate of anxiety was $22.7 \%$. Thus, among the sample of depressed SCD patients, $23.5 \%$ had only mild depression, $22.7 \%$ of the patients had moderate depression, $13.4 \%$ had moderately severe depression, while $9.2 \%$ of SCD patients were severely depressed. On the other hand, analysis of the GAD-7 questionnaire revealed that $30.3 \%$ had only mild anxiety, $13 \%$ had a moderate degree of anxiety, and $9.2 \%$ had severe anxiety.

Based on the cutoff percentage of depression rate (45.4\%), the rate of depression was most prevalent among the 30 -34 age group (27.8\%; $\mathrm{p}=0.902)$, and $51.9 \%$ males $(\mathrm{p}=0.078)$ were found to be more depressed than females. Regarding marital status, single patients had higher levels of depression $(57.4 \%, \mathrm{p}=0.976)$ than married and divorced patients. Furthermore, secondary educational levels and college level (40.7\%), (30\%) $(\mathrm{p}=0.610)$ retrospectively were more depressed than subjects who were diploma or with primary and intermediate levels of education. Approximately 63\% ( $\mathrm{p}=0.192)$ of SCD depressed individuals had monthly household incomes less than USD 1000. In terms of residential status, SCD patients in rented houses were found to have a more significant depression of $75.9 \%(p=0.132)$ than the owner.

Those who had a positive family history of sickle cell disease were more depressed $(88.9 \%$; $\mathrm{p}=0.016)$ than those who didn't have a history of the disease. Moreover, the unemployed patient had a significantly higher depression rate $(63 \% ; \mathrm{p}=0.047)$ than the employers. The relation between depression rate and sociodemographic characteristics (age, gender, marital status, employment status, monthly household income, and resident status) was statistically insignificant. In contrast, the depression rate was significantly associated with employment status and the family history of SCD, and the p-values are summed up in Table 2 .

\begin{tabular}{|c|c|c|c|c|c|c|}
\hline \multirow[t]{2}{*}{ Variable } & \multicolumn{2}{|c|}{ Depression } & \multirow[t]{2}{*}{ P-value } & \multicolumn{2}{|c|}{ Anxiety } & \multirow[t]{2}{*}{ P-value } \\
\hline & NO. & $(\%)$ & & NO. & $(\%)$ & \\
\hline Gender & & & $P=0.078$ & & & $P=0.296$ \\
\hline Male & 28 & $(38.9)$ & & 14 & (19.4) & \\
\hline Female & 26 & $(55.3)$ & & 13 & $(27.7)$ & \\
\hline Age & & & $P=0.902$ & & & $P=0.613$ \\
\hline 18-19 years & 1 & $(100)$ & & 0 & (0) & \\
\hline 20-24 years & 13 & $(46.4)$ & & 7 & (25) & \\
\hline 25-29 year & 8 & (42.1) & & 2 & (10.5) & \\
\hline 30-34 years & 15 & $(48.4)$ & & 8 & $(25.8)$ & \\
\hline 35-39 years & 9 & (40.9) & & 4 & $(18.2)$ & \\
\hline Over 40 years & 8 & $(44.4)$ & & 6 & (33.3) & \\
\hline Marital status & & & $P=0.976$ & & & $P=0.7$ \\
\hline Single & 31 & $(46.3)$ & & 14 & (20.9) & \\
\hline Married & 19 & $(44.2)$ & & 10 & (23.3) & \\
\hline Divorced or Widowed & 4 & $(44.4)$ & & 3 & (33.3) & \\
\hline Employment status & & & $P=0.047$ & & & $P=0.348$ \\
\hline Working in the public sector & 17 & (39.5) & & 7 & (16.3) & \\
\hline Self-employed & 3 & $(100)$ & & 1 & (33.3) & \\
\hline Unemployed & 34 & $(49.3)$ & & 19 & (27.5) & \\
\hline Retired & 0 & (0) & & 0 & (0) & \\
\hline
\end{tabular}




\section{Cureus}

\begin{tabular}{|c|c|c|c|c|c|c|}
\hline Residential status & & & $P=0.132$ & & & $P=0.257$ \\
\hline Owner & 13 & $(35.1)$ & & 6 & $(16.2)$ & \\
\hline Renter & 41 & (50) & & 21 & $(25.6)$ & \\
\hline Monthly household income & & & $P=0.192$ & & & $P=0.327$ \\
\hline Less than 1000 USD & 34 & $(52.3)$ & & 17 & (26.2) & \\
\hline 1000-2000 USD & 10 & $(30.3)$ & & 4 & (12.1) & \\
\hline 2000-3000 USD & 3 & (60) & & 2 & (40) & \\
\hline More than 3000 USD & 7 & $(43.8)$ & & 4 & (25) & \\
\hline Education & & & $P=0.610$ & & & $P=0.103$ \\
\hline Primary level & 5 & $(62.5)$ & & 4 & (50) & \\
\hline Intermediate level & 7 & $(46.7)$ & & 6 & (40) & \\
\hline Secondary level & 22 & (50) & & 8 & (18.2) & \\
\hline Diploma & 3 & (30) & & 1 & (10) & \\
\hline College level & 17 & $(40.5)$ & & 8 & (19) & \\
\hline Family history of SCD & & & $P=0.016$ & & & $P=0.369$ \\
\hline Yes & 48 & $(51.1)$ & & 23 & (24.5) & \\
\hline No & 6 & (24) & & 4 & (16) & \\
\hline
\end{tabular}

TABLE 2: Statistics and $p=v a l u e s$ of the inferential statistical analysis of depression and anxiety levels with different sociodemographic variables

The rate of anxiety is $22.7 \%$, which is for moderately and severely anxious patients. Our study showed that anxiety in relation to sociodemographics was higher in the $30-34$ age group (29.6\%) than in the other age groups. And, males were more depressed $51.9 \%$ than females. Moreover, SCD patients in secondary education level were more anxious (29.6\%) than others. However, there was no significant association between the anxiety rate and all sociodemographic characteristics. The p-value is summed up in Table 2.

\section{Discussion}

This study aimed to determine the prevalence and identify the relationship of sociodemographics with depression and anxiety of SCD patients at King Abdulaziz University Hospital, Jeddah, Saudi Arabia. Other researches found that depressed patients will have significantly higher health care utilization and inpatient costs than nondepressed patients [17-19]. So determining the risk factors that increase a psychological disorder in SCD patients will be a chance to decrease the cost and provide much better medical care to these patients.

There is a wide difference in the prevalence that has been reported in the researches across different countries. According to the depression categories and based on the cutoff, the depression rate was $45.4 \%$, which was represented by the (moderate-moderately severe-severe) depression categories; however, the nondepressed is a little higher (54.1\%) than depressed patients, which is represented by (nondepressedmild) depression categories. These findings were compatible with a study conducted in Tabuk that reported a depression rate was $36 \%$ and nondepressed SCD patients were 64\% [11]. Furthermore, we found that the rate of anxiety in our study was $22.7 \%$, which was less than that reported by Tabuk and Levenson et al. $[11,20]$.

Regarding gender, our results showed the depression and anxiety rate among males was higher than females $(p>0.05)$. These findings are conflict with the results conducted by Tabuk and Gana's study that showed the rate of depression is higher in females $[11,21]$. Similarly, the results reported by the Southern Region of Saudi Arabia also show the rate of depression and anxiety is higher in females [19]. However, these results failed to indicate any statistical significance in our study.

Our study showed the median age of the whole patient was $32 \pm 9$. Hence, the prevalence of depression rate was highest among the 30-34 age group. In contrast, other researchers (Adzika et al.) reported a significantly high depression rate in the 40 to 49 -year-old age group [21]. 
According to marital status, the majority of the SCD patients were single. Therefore, the single patients had higher levels of depression (57.4\%) and anxiety (51.9\%) than married and divorced patients. In addition, 31 single patients were depressed, which represented (46\%) of the total 67 single patients who participated in our research. This is in line with another study done in New York, which found that social support was associated with high self-esteem, which in turn increased optimism and was related to decreased depression [22].

Patients with sickle cell disease who had higher education levels such as secondary and college educational levels were more depressed and anxious. Similar results were revealed by a study in the Tabuk region of Saudi Arabia [11]. These findings contradict Ghana's study that reported a significantly high depression score for individuals with only primary education [21]. According to the employment status in our results, $70 \%$ of unemployed people have more anxiety. In addition, $63 \%$ of unemployed individuals had higher levels of depression than others, which revealed a statistically significant association $(\mathrm{p}<0.05)$. A study published in Jamaica about the prevalence of depression in SCD patients reported that unemployment was linked to depression in people with SCD, which is similar to our study [23].

More than half the patients (48) who had a positive family history (94) are considered depressed (pvalue $<0.5$ ), and they have faced difficult psychological moments in their life. Moreover, a Saudi paper published in 2018 showed the same results that we extracted, as it reported that sickle cell patients face psychological obstacles throughout their life due to the disease [11]. However, the relation was not entirely significant. Unfortunately, it was concluded that having a first-degree relative in the family with an anxietyrelated illness increases the likelihood that a new family member will develop anxiety problems, based on a case-control study published in 2008 [24].

The limitation of our research was a phone-based questionnaire. Hence, we didn't see the patient's reactions and determine whether the answers are truthful. Furthermore, the coronavirus disease 2019 (COVID-19) pandemic may affect the percentage and increase the incidence of anxiety [25]. In addition, we recognize that some patients may intentionally avoid answering some suicidal and harm-self questions, which may be related to religious aspects or due to fear of revealing their thoughts. Therefore, we recommend clarifying the pathophysiology of depression diseases, and we think that a clinical interview compared to the phone-based questionnaire may have been a more accurate approach.

\section{Conclusions}

This study aimed to obtain the prevalence of depression and anxiety in sickle cell patients at King Abdulaziz University Hospital in Jeddah. The results showed that nearly half (45.4\%) of the participants in this research study have depression. However, male patients had slightly higher rates of depression and anxiety than female patients. Moreover, the research showed a significant relationship between depression rates and employment status. More research like this is needed in Saudi Arabia's western region to obtain better insight into the psychosocial impact of SCD patients, gather more data, and formulate an appropriate plan to deal with psychological and social issues.

\section{Additional Information \\ Disclosures}

Human subjects: Consent was obtained or waived by all participants in this study. King Abdulaziz University Hospital ethics research committee issued approval 409-21. Animal subjects: All authors have confirmed that this study did not involve animal subjects or tissue. Conflicts of interest: In compliance with the ICMJE uniform disclosure form, all authors declare the following: Payment/services info: All authors have declared that no financial support was received from any organization for the submitted work. Financial relationships: All authors have declared that they have no financial relationships at present or within the previous three years with any organizations that might have an interest in the submitted work. Other relationships: All authors have declared that there are no other relationships or activities that could appear to have influenced the submitted work.

\section{Acknowledgements}

The authors acknowledge that Dr. Adel F. Al-Marzouk and Dr. Norah I. Alrefaie shared first authorship.

\section{References}

1. Lehmann H, Maranjian G, Mourant A: Distribution of sickle-cell haemoglobin in Saudi Arabia . Nature. 1963, 198:492-3.

2. Al-Qurashi MM, El-Mouzan MI, Al-Herbish AS, Al-Salloum AA, Al-Omar AA: The prevalence of sickle cell disease in Saudi children and adolescents. Saudi Med J. 2008, 29:1480-3.

3. Ashorobi D, Bhatt R: Bone Marrow Transplantation In Sickle Cell Disease. StatPearls [Internet], Treasure Island (FL); 2021.

4. Rees DC, Williams TN, Gladwin M: Sickle-cell disease. Lancet. 2010, 376:2018-31. 10.1016/s01406736(10)61029-X 
5. Toumi ML, Merzoug S, Boulassel MR: Does sickle cell disease have a psychosomatic component? A particular focus on anxiety and depression. Life Sci. 2018, 210:96-105. 10.1016/j.lfs.2018.08.066

6. Olson SH, Iyer S, Scott J, et al.: Cancer history and other personal factors affect quality of life in patients with hepatitis C. Health Qual Life Outcomes. 2005, 3:39. 10.1186/1477-7525-3-39

7. Egede LE: Effects of depression on work loss and disability bed days in individuals with diabetes . Diabetes Care. 2004, 27:1751-3. 10.2337/diacare.27.7.1751

8. The American Psychiatric Publishing: Textbook of Psychosomatic Medicine. James L Levenson (ed): The Academy of Psychosomatic Medicine, Washington D.C; 2005.

9. Bair MJ, Robinson RL, Katon W, Kroenke K: Depression and pain comorbidity. A literature review . Arch Intern Med. 2003, 163:2433-45. 10.1001/archinte.163.20.2433

10. Katon W, Lin EH, Kroenke K: The association of depression and anxiety with medical symptom burden in patients with chronic medical illness. Gen Hosp Psychiatry. 2007, 29:147-55. 10.1016/i.genhosppsych.2006.11.005

11. Zahrani OS, Mukhtar O, Subaie MA, Howiti WE: Systematic psychiatric assessment of patients with sickle cell disease. Saudi Med J. 2019, 40:59-65. 10.15537/smj.2019.1.22919

12. Alhomoud MA, Gosadi IM, Wahbi HA: Depression among sickle cell anemia patients in the Eastern Province of Saudi Arabia. Saudi J Med Med Sci. 2017, 6:8-12. 10.4103/sjmms.sjmms_123_16

13. Alsubaie SS, Almathami MA, Abouelyazid A, Alqahtani MM: Prevalence of depression among adults with sickle cell disease in the southern region of Saudi Arabia. Pak J Med Sci. 2018, 34:929-33. 10.12669/pjms.344.14760

14. Kroenke K, Spitzer RL, Williams JB: The PHQ-9. validity of a brief depression severity measure . J Gen Intern Med. 2001, 16:606-13. 10.1046/j.1525-1497.2001.016009606.x

15. Spitzer RL, Kroenke K, Williams JB, Löwe B: A brief measure for assessing generalized anxiety disorder. The GAD-7. Arch Intern Med. 2006, 166:1092-7. 10.1001/archinte.166.10.1092

16. Manea L, Gilbody S, McMillan D: Optimal cut-off score for diagnosing depression with the Patient Health Questionnaire (PHQ-9): a meta-analysis. CMAJ. 2012, 184:E191-6. 10.1503/cmaj.110829

17. Adam SS, Flahiff CM, Kamble S, Telen MJ, Reed SD, De Castro LM: Depression, quality of life, and medical resource utilization in sickle cell disease. Blood Adv. 2017, 1:1983-92. 10.1182/bloodadvances.2017006940

18. Onyeaka HK, Queeneth U, Rashid W, Ahmad N, Rajan SK, Jaladi PR, Patel RS: Impact of depression in sickle cell disease hospitalization-related outcomes: an analysis of the national inpatient sample (NIS). Medicina (Kaunas). 2019, 55:10.3390/medicina55070385

19. Lee S, Vania DK, Bhor M, Revicki D, Abogunrin S, Sarri G: Patient-reported outcomes and economic burden of adults with sickle cell disease in the United States: a systematic review. Int J Gen Med. 2020, 13:361-77. 10.2147/IJGM.S257340

20. Levenson JL, McClish DK, Dahman BA, et al.: Depression and anxiety in adults with sickle cell disease: the PiSCES project. Psychosom Med. 2008, 70:192-6. 10.1097/PSY.0b013e31815ff5c5

21. Adzika VA, Glozah FN, Ayim-Aboagye D, Ahorlu CS: Socio-demographic characteristics and psychosocial consequences of sickle cell disease: the case of patients in a public hospital in Ghana. J Health Popul Nutr. 2017, 36:4. 10.1186/s41043-017-0081-5

22. Symister P, Friend R: The influence of social support and problematic support on optimism and depression in chronic illness: a prospective study evaluating self-esteem as a mediator. Health Psychol. 2003, 22:123-9. 10.1037/0278-6133.22.2.123

23. Asnani MR, Fraser R, Lewis NA, Reid ME: Depression and loneliness in Jamaicans with sickle cell disease . BMC Psychiatry. 2010, 10:40. 10.1186/1471-244X-10-40

24. McLaughlin KA, Behar E, Borkovec TD: Family history of psychological problems in generalized anxiety disorder. J Clin Psychol. 2008, 64:905-18. 10.1002/jclp.20497

25. Tezol O, Unal S: Anxiety level and clinical course of patients with sickle cell disease during the COVID-19 outbreak. Arch Pediatr. 2021, 28:136-40. 10.1016/j.arcped.2020.12.004 